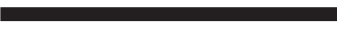

9o Passo: Os alunos irão realizar uma sequencia de

10 Passo: Em pé 0 aluno deve elevar o joelho até a cintura e abaixar de acordo com o ritmo da musica, alternando as pernas.

20 Passo: Em pé com as pernas abertas na mesma linha do ombro, com os joelhos semi-flexionados, os alunos irão abaixar o tronco para a direita e para a esquerda de acordo com o ritmo da musica.

3o Passo: Em pé com os pés unidos os alunos deverão dar dois saltos lateralmente e após dar dois saltos para o outro lado também lateralmente, os braços deverão estar estendidos e acima da cabeça alternando de acordo com o ritmo da musica.

4o Passo: Em pé o aluno deve cruzar uma perna de cada vez na frente da outra no ritmo da musica, os braços devem estar estendidos acima da cabeça batendo palma quando a perna se posicionar na frente da outra.

5o Passo: Com os joelhos semi-flexionados, o aluno devera colocar as mãos no joelho, o tronco deve estar pouco inclinado á frente, na batida da musica ele deverá elevar um ombro de cada vez, o aluno irá alternar elevando duas vezes o mesmo ombro.

60 Passo: Em pé o aluno irá realizar uma sequencia de pernas, primeiro ele irá colocar uma perna lateralmente, a outra perna ira se posicionar atrás, a perna que estava na lateral ira abrir de novo lateralmente, $\mathrm{e}$ a perna que estava posicionada atrás ira pisar no chão lateralmente marcando o tempo da musica, ele ira realizar a mesma sequencia do lado oposto.

70 Passo: Em pé com os pés unidos os alunos irão flexionar os joelhos no ritmo da musica, os braços devem estar estendidos na frente do corpo movimentando de um lado para o outro de acordo com os joelhos. 80 Passo: Em pé com o tronco voltado para uma diagonal, pés na mesma largura do ombro, os alunos irão com o braço direito estendido á frente do corpo e movimenta-lo junto com o joelho e pé esquerdo que estará se movimentando para o lado de fora do corpo. Eles realizarão esse movimento para o outro lado.

RESUMO
AUTORA:

Rosikelle K. R. de Sousa ${ }^{1}$

${ }^{2}$ Universidade de Pernambuco

O Esporte enquanto conteúdo

\section{nas aulas de Educação Física}

braços, primeiro eles irão elevar acima da cabeça o braço direito duas vezes, depois o braço esquerdo, após os dois braços para baixo, e por ultimo os dois braços para cima.

10ํ Passo: Em pé os alunos irão ficar equilibrados em uma perna, enquanto a outra perna irá ficar estendida a frente do corpo, os braços devem estar estendidos a frente do corpo acompanhando a perna, fazendo um movimento de chute com a perna.
PALAVRAS CHAVE:

Esporte. Esporte coletivo. Educação Física.

O esporte tornou-se, nos últimos anos, o principal, senão o único conteúdo escolhidos pelos professores nas aulas de Educação Física, em detrimento ao demais conteúdos presente na educação física. Essa pesquisa teve como objeto de estudo analisar a importância do esporte coletivo como conteúdo nas aulas de educação física. Pretendeu-se, especificamente, caracterizar o papel da educação física no ensino fundamental I e II; Identificar os tipos de modalidades esportivas nas aulas de educação física do ensino fundamental I e II. A presente pesquisa foi orientada para responder como as escolas tratam o esporte nas aulas de educação física e como os educandos do ensino fundamental I e II encaram as práticas esportivas coletivas e de rendimento durante estas aulas? A metodologia de pesquisa se deu através de levantamentos bibliográficos e virtuais (web), para uma compreensão dos aspectos referentes ao esporte nas escolas. 0 tema é relevante e pode incentivar educadores a utilizarem com mais frequência os esporte nas aulas de educação, porém, enquadrando-o no projeto pedagógico da instituição, com o intuito de promover o esporte com finalidades educativas e não meramente competitivas. 


\section{The Sport as content}

\section{in the Physical Education classes}

\section{ABSTRACT}

In recent years, the sport has become the main if not the only content chosen by teachers in Physical Education classes, to the detriment of others present contents in Physical Education. This purpose of this research was to analyze the importance of team sport as a subject in Physical Education classes. It was intended specifically to characterize the role of Physical Education in elementary school I and II; Identify the types of sports in physical education classes elementary school I and II. This research was geared to answer how schools treat the sport in Physical Education classes and how the students of the elementary school I and II face the team sports and yield during these classes? The research methodology was through bibliographic and virtual surveys (web), for an understanding of aspects relating to sport in schools. The theme is relevant and can encourage educators to use more often the sport in Physical Education classes, but framing it in the pedagogical project of the institution, in order to promote the sport with educational purposes and not merely competitive

KEY WORDS:

Sport. Team sports. Physical Education.

\section{INTRODUÇÃo}

Em virtude da própria vivência e a atual situação da educação física escolar percebe-se que, atualmente, existe uma predominância da prática esportiva fazendo com que uma minoria talentosa participe das aulas enquanto uma grande maioria fique sem participar da mesma, pois o que é valorizado são apenas os gestos técnicos do esporte e que não tem habilidades acaba por ser excluídos das aulas.

Para Tubino ${ }^{(11)}$, o esporte pode ser visto a partir de três dimensões: esporte-educação, visando o caráter formativo; esporte-participação, onde a finalidade é a participação do praticante e o esporte-performance, com vistas apenas ao rendimento dentro de uma obediência rígida às regras. Percebe-se, atualmente, uma tendência em escolher o esporte de rendimento (ou de performance) nas aulas de Educação Física na escola, em detrimento das demais dimensões do esporte, estimulando-se a competitividade entre os alunos, causando dessa forma o afastamento de alguns que não se adequam a essa modalidade esportiva ou que não se sentem capazes de competir.

Segundo Barreto ${ }^{(1)}$, a Educação Física nas escolas possui outros conteúdos, tais como a dança, os jogos, as lutas, as brincadeiras, sendo o esporte um destes. É na escola que a conotação de esporte deve ser diferente do esporte de alto nível, apesar de alguns professores de Educação Física insistirem em alto rendimento.

Desta forma, este trabalho tem como objetivo analisar, à luz de diversos autores, a importância do esporte coletivo como conteúdo nas aulas de educação física. Identificando o que caracteriza o papel da educação física no ensino fundamental I e II; E o s tipos de modalidades esportivas propostas nas aulas de educação física do ensino fundamental I e II. Essa esportivização nas aulas de Educação física tem chamado a atenção no meio educativo e levantado questionamentos e discussões, uma vez que provoca a exclusão de alguns que não se sentem aptos par esse tipo de esporte, gerando até o desinteresse destes pela prática de atividade física. Conforme Lakatos e Marconi ${ }^{\left({ }^{8}\right)}$ farei uso da técnica da pesquisa bibliográfica, utilizando as fontes bibliográficas do tipo de publicações, encontradas em livros, artigos, publicações avulsas, etc. Procurando analisar dessa forma conceitos e discussões já elaboradas por diversos autores, de maneira a conhecer melhor a problemática em foco

\section{OESPORTE NAS AULAS}

DE EDUCAÇ̃̃o FÍSICA

A Educação Física é compreendida como um componente curricular da educação básica que tem como finalidade inserir o aluno no estudo da cultura corporal dos movimentos, proporcionando a inter-relação e o exercício da cidadania. Desse modo, a Educação Físi- 
ca Escolar promove a socialização sistematizada, contribuindo para a transformação das relações excludentes, através da vivência de relações participativas e solidárias. Ela pode "garantir o acesso aos jogos, ginásticas, danças, lutas e esportes, resgatando a cultura corporal dos alunos e compreendendo os seus significados históricos mediante a reflexão da cultura do seu corpo" $(6, p .257)$

A cultura corporal do aluno seria resgatada ao se possibilitar a reflexão sobre o seu movimentar cotidiano, sobre os jogos populares e pela possibilidade de construção de jogos. Assim, o aluno tornar-se-ia um agente crítico e produtor de conhecimento escolar (p. 257).

Ou seja, esse entendimento revoluciona a prática da Educação Física Escolar, contribuindo para o alcance da autonomia individual e coletiva, valorizando a solidariedade, igualdade, respeito e participação.

Dentro do contexto escolar, a Educação Física tem no movimento corporal um meio e um fim para alcançar seu objetivo. "O movimento pode ser entendido como uma atividade, no caso corporal, que se manifesta através do jogo, do esporte, da dança ou da ginástica" (2, pp. 25-26).

A autora elucida que é fácil perceber que a escola, mesmo não tendo estrutura, assumiu o ensino do esporte como única estratégia.

Conforme o exposto, percebe-se que a escola passou a encarar o esporte como uma prática permanente em seu cotidiano, deixando de lado os outros conteúdos da educação física.

Na visão de Kunz (apud 10), o esporte de rendimento utilizado na escola, tem como conseqüência a vivencia de um grupo pequeno de alunos que depararão com o sucesso e um grupo maior que vivenciarão o fracasso, remetendo para o professor um grande engano pedagógico

Betti (2) fala que o esporte nas aulas de educação física tem origem histórica, iniciando na Revolução Industrial, praticado pela aristocracia e depois pela classe média, em associações esportivas e clubes. A partir do século XIX, a expansão do esporte se espalhou por quase todo o mundo. No início da década de 70, a esportivização atinge seu auge utilizando o binômio Educação Física/ Esporte. Desse modo, "sendo repassado nas escolas, é aceito como um saber inquestionável e evidente, sem transformações didáticas que o possam problematizar, tornando o indivíduo autônomo e capaz de competência social, um ser Sujeito de sua ação" (p.26).

No pensamento de Porcher (apud 2), aumentar ou diminuir o número de horas dedicadas ao esporte não o tornarão necessariamente educativos. É preciso aceitar que o esporte (queira-se ou não) tornou-se um fenômeno social massivo devido à mídia, ao mundo dos negócios, aos periódicos especializados... 0 esporte exerce um papel social (e isso não é depreciativo) e, por outro lado, é constituído pela atividade física pura. Não é possível adotar a "política do avestruz" ocultando qualquer um destes papéis (p. 27)
Lettnin ${ }^{(9)}$ afirma que: A prática esportiva ensina uma série de regras, as quais os alunos aprendem a respeitar, desenvolvendo o senso crítico, a cooperação e outros importantes aspectos educacionais. Educar pela prática esportiva significa expor e aproximar os alunos de suas limitações, como um ser humano que pensa e reage a estímulos (p. 31).

De acordo com o descrito, observa-se que as escolas não podem coibir a prática do esporte nas aulas de educação física e sim procurar enquadrá-lo no projeto pedagógico da instituição, com o intuito de promover o esporte com finalidades educativas.

Bracht et. al. ${ }^{(4)}$, reconhecem que:

A influência do esporte no sistema escolar é de tal magnitude que temos, então, não o esporte da escola mas sim o esporte na escola. Isso indica a subordinação da educação física aos códigos/sentido da instituição esportiva, caracterizando-se o esporte na escola como um prolongamento da instituição esportiva.

Apesar de haver muitos obstáculos no ensino do esporte nas aulas de educação física, é impossível negar aos discentes o aprendizado deste. É preciso que os profissionais de educação física saibam trabalhá-lo de maneira adequada e a escola invista em espaço, conhecimento e procedimentos próprios do esporte para serem repassados aos alunos. Pois é por meio do esporte coletivo que o educando consegue se auto afirmar, uma vez que desenvolverá seu potencial competitivo, além de trabalhar corpo e mente como também estabelecer relações de parcerias construtivistas.

Portanto no contexto escolar, toda proposta pedagógica voltada para prática esportiva deve ser orientada para desenvolvimento do educando, sendo necessário haver uma flexibilidade em todos os procedimentos esportivos para que ocorra a participação de todos sem distinção.

\section{IMPLICAÇÕES DO ESPORTE}

\section{DE RENDIMENTO PARA O ALUNO}

A escola assumiu o ensino do esporte, praticamente como única estratégia. E esta é uma constatação fácil de ser percebida em toda instituição escolar, tenha ela ou não estrutura para tal. Segundo Bracht et al. ${ }^{(4)}$ apesar da Educação Física haver lançado mão de um amplo leque de objetivos, como o desenvolvimento do sentimento de grupo, a socialização, cooperação, etc., o objetivo da escola é tão somente a aprendizagem do esporte, ficando a ginástica e a corrida, por exemplo, como simples aquecimento, além dos jogos populares terem sido transformados em "jogos pré-desportivos"

No período dos anos 50, a Educação Física passou a ser influenciada pelo esporte, que adquiri popularidade na cultura do movimento, tornando-se um elemento hegemônico. Desta forma, "a Educação Física Escolar passa a ser um braço da instituição esportiva. Os princípios da Educação Física passam a ser os princípios do esporte" (6,p.97). 
Para Libâneo (apud 6), os conteúdos da educação física são compostos dos seguintes elementos: "conhecimentos sistematizados; habilidades e hábitos; atitudes e convicções" (p.189). Nos sistematizados vistos na Educação Física escolar, é observado como consenso de todos a predominância do esporte. Mesmo ausentes de espaços físicos adequados, os profissionais de educação física priorizam o ensino do voleibol e do futebol ${ }^{(6)}$.

No pensamento de Bracht (apud 6), o esporte na escola seria um braço prolongado da própria instituição esportiva, e, consequentemente, o trabalho de seus códigos como atlético-esportivo, competição, comparação de rendimentos e recordes, regulamentação rígida, sucesso esportivo e sinônimo de vitória, racionalização de meios e técnicas (p.190).

Assim, verifica-se que a escola torna o esporte uma extensão, sendo trabalhado diferentes modalidades, e promovendo dessa forma o incentivo à competição.

Mesmo sendo alvo de muitas discussões polêmicas, o esporte tornou-se um conteúdo oficial da Educação Física Escolar, defendido no Art. 27ํ da Lei n 9.394 .96 que afirma ser atribuição da escola a promoção do esporte educacional. Vale ressaltar que as perspectivas curriculares da Educação Física Escolar estão diretamente ligadas à construção do Projeto Político-Pedagógicos das escolas.

Ao ser inserido nas aulas de educação física escolar, o esporte de rendimento acaba por estimular um tipo de educação que colabora para o indivíduo introduzir valores, regras de comportamento conforme as exigências da sociedade, pois o esporte de rendimento traz no seu contexto forte orientação na competição e no rendimento ${ }^{(4)}$.

O esporte coletivo tem a função de proporcionar ao aluno o prazer e a adesão a uma prática corporal, além de promover o desenvolvimento interpessoal, o qual terá a oportunidade de interagir coerentemente com sua equipe e seus adversários. Neste aspecto, a iniciação se diferencia do treinamento esportivo, necessitando ser orientada adequadamente por profissionais competentes que valorizem os discentes em sua totalidade.

Se o aluno aprende os fundamentos técnicos e táticos de um esporte coletivo, precisa também aprender a organizar-se socialmente para praticá-lo, precisa compreender as regras como um elemento que torna o jogo possível (portanto é preciso também que aprenda a interpretar e aplicar as regras por si próprio), aprender a respeitar o adversário como um companheiro e não um inimigo, pois sem ele não há competição esportiva ${ }^{(3)}$.

Vale ressaltar que o esporte não deve ser aniquilado das aulas de educação física, mas deve ser praticado de acordo com o desenvolvimento de cada faixa etária. A criança deve sim ser estimulada para a prática esportiva, porém o docente precisa respeitar os estágios de desenvolvimento motor, a melhor fase para o educando ter suas habilidades trabalhadas e sua maturidade para acompanhar alguma modalidade esportiva.

\section{RESULTADOS E DISCUSSÃo}

0 processo atual de ensino-aprendizagem da educação física nas escolas está orientado pelo sistema esportivo, onde o esporte coletivo é o principal método utilizado pelos profissionais de educação física, os quais treinam seus alunos nas modalidades de voleibol, basquetebol, handebol e futebol. A ênfase do ensino nas aulas de educação física está predominantemente voltada para esse tipo de pratica, transformando-o em alto rendimento. Técnicas e habilidades esportivas, treinamento e rendimento têm sido fontes de informações para seleção de conteúdos. Neste contexto, as aulas de educação física têm causado aflições e ansiedades nos alunos, os quais são levados a destacar-se nas competições caso contrario serão excluídos das aulas de educação física.

Assim, nas aulas de Educação Física, o esporte que antes possuía características informais em seus conteúdos, com alterações nas regras e caráter competitivo e cooperativo, passa a adotar uma postura mais rígida, normatizando as regras que são controladas exclusivamente pelos professores, os quais direcionam a prática para o lado mais competitivo, sendo a principal meta nas aulas de educação física escolares ${ }^{(5)}$.

O esporte está enraizado culturalmente em nossa sociedade e, após inserido na escola, provocou grande influência nas aulas de educação física, sendo muitas vezes o único conteúdo ensinado pelos professores. No entendimento dos autores, o esporte deve sim estar presente na escola, essencialmente na disciplina de Educação Física, porém devemos fazer dele um meio para a formação dos alunos.

Vale salientar que existem muitas sugestões de autores para transformar a maneira de repensar o esporte na escola, como também as formas de atividades a serem adotadas. Porém, há muitos entraves no processo de inserção do esporte no contexto escolar, como: resistências por parte dos educadores, o impasse a respeito da escolha do conteúdo a ser trabalhado no ano letivo e a questão espaço físico da instituição ${ }^{(2)}$.

Neste sentido, um dos elementos fundamentais para o processo de aprendizagem do educando no esporte, é iniciá-lo por meio do jogo. Porém, não basta adotar o jogo como elemento nas aulas de educação física. É necessário que os educadores produzam modificações na estrutura do jogo, a fim de atenuar as regras e adequá-las em prol do aluno.

"O jogo como mediador entre a criança e o esporte, a ser potencializado pelo professor, permite uma flexibilidade de regras que possibilita ao professor tornar adequado à criança praticar o esporte coletivo". Bracht et al. (4) afirmam que "O jogo satisfaz necessidades das crianças, especialmente a necessidade de "ação" (p.65). Estes autores relatam que o jogo tem o propósito/objetivo de acentuar o desenvolvimento da criança, além de determinar sua afetividade.

Galatti et al. ${ }^{(7)}$ acrescentam que existe um outro exemplo bastante relevante para iniciação do aluno na prática esportiva que é a inclusão deles em atividades competitivas não formais, principalmente em festivais esportivos que muitas escolas adotam. São nesses 
momentos que ocorrem uma flexibilidade satisfatória, pois as regras são livres, todos participam dos jogos diversas vezes e a relação interpessoal ocorre com mais afinco.

Corrêa e Moro ${ }^{(6)}$ observam que a Educação Física em algumas escolas proporcionaria um encontro de vivências e em outras serviria como liberação de energia, contribuindo para o afastamento dos jovens das drogas e da prostituição. A Educação Física também poderia contribuir na parte motora e no movimento do corpo, principalmente nas séries iniciais, tendo como objetivo o desempenho no esporte. Uma outra abordagem seria proporcionar aos alunos o desenvolvimento de atividades que contribuísse para aquisição de uma vida saudável.

Portanto, é por meio do esporte coletivo que o educando consegue se auto-afirmar, uma vez que desenvolverá seu potencial competitivo, além de trabalhar corpo e mente, como também estabelecer relações de parcerias construtivistas além de contribuir para que os alunos tenha um "estilo" de vida mais saudável.

\section{CONSIDERAÇõES FINAIS}

Sabe-se que é uma tendência a presença do esporte das aulas de Educação Física, principalmente estimulando a competitividade entre os alunos, onde os mais hábeis se destacam, em detrimento dos menos capacitados para determinadas modalidades esportivas. Percebe-se, diante do estudo aqui realizado, que o esporte deve estar presente como conteúdo nas aulas de Educação Física. No entanto, deve estar orientado para o desenvolvimento do educando, sendo necessário que haja uma flexibilidade em todos os procedimentos esportivos a fim de que ocorra a participação de todos sem distinção.

Diante do exposto, fica evidente que o esporte praticado nas aulas de educação física proporcionam aos discentes inúmeras possibilidades de vivenciar experiências afetivas $\mathrm{e}$ sociais. A interação com o professor, com a equipe e também com os adversários, torna as aulas uma oportunidade única para o desenvolvimento psicomotor dos envolvidos. Nos jogos esportivos coletivos, a visão simplista do esporte precisa ser abandonada, priorizando o trato de maneira sócio- cultural de caráter educativo. Desse modo, os procedimento pedagógicos nas aulas de educação física precisam de flexibilidade, respeitando sempre a individualidade cada aluno.

Portando, garantir um ambiente que proporcione aos educandos atividades esportivas construtivas, é função primordial de cada instituição de ensino, proporcionado a cada aluno o prazer de praticar esportes.

\section{REFERÊNCIA}

1. BARRETO, Guimarães. Esporte e saúde. Disponivel em www.cdcc.usp.br Acesso em 28/02/2012

2. BETTI, Irene Conceição Rangel. Esporte na Escola: Mas é só isso, professor?. Revista Motriz, v. 1, n. 1, p. 25 -31, junho/1999. Disponível em: www.rc.unesp.br/ ib/efisica. Acesso em 25/06/2009

3. BETTI, M.; ZULIANI, L. R. Educação física escolar: uma proposta de diretrizes pedagógicas. Revista Mackenzie de Educação Física e Esporte, São Paulo, v. 1 n. 1 , jan./dez. 2002

4. BRACHT, Valter; FILHO, Lino Castellani; SOARES, Carmem Lúcia; TAFFAREL, Celi Nelza Zulke; VARJAL, Elizabeth e ESCOBAR, Micheli Ortega. Metodologia do Ensino de Educação Física.São Paulo: Cortez, 2009. 5. DARIDO, Suraya Cristina e BARROSSO, André Luís Ruggiero. Escola, Educação Física e Esporte: possibilidades pedagógicas. Disponível em: http://www.refeld. com.br. Acesso em 18/03/2012

6. CORRÊA, Ivan Livindo de Senna e MORO, Roque uiz. Educação Física escolar: reflexão e ação curricular. Ijuí/RS: Unijuí, 2004

7. GALATTI, Larissa Rafaela; FERREIRA, Henrique Barcelos; SILVA, Ylane Pinheiro Gonçalves e PAES, Roberto Rodrigues. Pedagogia do esporte: procedimentos pedagógicos aplicados aos jogos esportivos coletivos. Disponivel em: www.fef. unicamp br. Acesso em 18/03/2012

8. LAKATOS, E. M., MARCONI, M. A. Fundamentos de metodologia científica. São Paulo: Atlas, 1991

9. LETTNIN, Carla da Conceição. Esporte escolar: Razão e Significados. Disponível em: www.diaadiaeducacao.pr.gov.br. Acesso em: 18/03/2012

10. SOUZA JÚNIOR, Marćíio. 0 Saber e o Fazer Pedagógicos: A Educação Física como componente curricular... ? ... isso é História!. Recife: EDUPE, 1999

1. TUBINO, M. J. G. Dimensões sociais do esporte. ed. São Paulo: Cortez, 2001 